$$
\text { DOEFER/25094-T2 }
$$

\title{
1992 Annual Report to the National Science Foundation
}

\author{
The Geometry Center \\ University of Minnesota
}

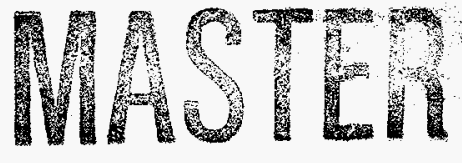

\section{DISCLAIMER}

\begin{abstract}
This report was prepared as an account of work sponsored by an agency of the United States Government. Neither the United States Government nor any agency thereof, nor any of their employees, makes any warranty, express or implied, or assumes any legal liability or responsibility for the accuracy, completeness, or usefulness of any information, apparatus, product, or process disclosed, or represents that its use would not infringe privately owned rights. Reference herein to any specific commercial product, process, or service by trade name, trademark, manufacturer, or otherwise does not necessarily constitute or imply its endorsement, recommendation, or favoring by the United States Government or any agency thereof. The views and opinions of authors expressed herein do not necessarily state or reflect those of the United States Government or any agency thereof.
\end{abstract}




\section{DISCLAmIER}

Portions of this docoment may be illegible in electronic image products. Images are produced from the best available original docoment. 
I. Summary of Research 


\section{Research}

The Center research program has a number of different aspects. The work over the past year includes the following.

\section{Research software}

\section{The Surface Evolver}

The Center sponsors both new programs, and continued development of existing software. This past year, Ken Brakke was in full time residence in the Center on a sabbatical from Susquehenna University. Thus, development of his Evolver program, in response to requests by researchers, strongly moved forward. Evolver has become the standard software tool used in computing optimal geometries. For example, it is being used at Martin Marietta for designing space rockets, and it has been used (Concus, Finn) to design an experiment in capillary surfaces carried out on one of the space flights. The Evolver manual is issued as a Center preprint.

\section{Interprogram communication}

In this direction, the Center is sponsoring Henry Cejtin and Igor Rivin under an Exploratory Research grant. They are developing a prototype system of a number of independent modules, whose behavior is completely described by an external specification, and a communication substrate which would allow these modules to communicate in a flexible way. In addition, the system will be designed as to make it possible to run different modules on different computers, possibly of differing architecture.

\section{Geom and Cweb}

Staff member Silvio Levy completed the writing of Geom, a Latex style and supporting program, based on macros previously used for the books written at the Center. This was made publicly available in the summer. In addition, he made a substantial revision in the Cweb programming tool, which he wrote in 1987 based on Don Knuth's Web. The changes were made in cooperation with Knuth and were intended to provide support for Cweb's widely increasing user base.

\section{CADiff}

Center postdoc Paul Burchard is working on his CADiff (Computer-Aided Differential Geometry) project.

Differential geometry is the study of smooth shapes. Computers promise to help us understand these shapes by giving us a "virtual reality" in which we can experience them in ways not possible or practical in real life. The possibilities are exemplified by software such as the Center's Geomview program, which among other things, can enter a virtual reality in which the user experiences hyperbolic space.

It turns out that one of the greatest barriers to using computers for geometric experimentation is the time and effort required to create the shapes for the computer in the first place. The difficulty is that computers don't yet speak the language of differential geometry. At the lowest level, computers only understand elementary shapes like points, lines, and polygons. Over this, a layer of software has developed that often allows shapes to be specified by explicit formulas in terms of spatial coordinates (e.g., $y=x^{2}$ ).

In differential geometry, however, shapes are most naturally described "implicitly* by their geometric properties. For example, we'd like to be able to draw an irregular loop 
of wire and tell the computer, "OK, stretch a soap film over that wire" (a soap film has the geometric property of having the least area of any surface stretched over the wire). Most implicit requests of this nature cannot now be handled by the computer, and it is usually necessary go back to pencil and paper, or to develop specialized software to translate the particular request into the explicit forms understood by the computer. Both of these methods take a lot of time and disrupt the flow of exploration.

The CADiff software Burchard is developing at the Center, in collaboration with Barry Merriman of UCLA, is designed to help close this gap by allowing the user to directly express a wide variety of geometric properties, providing automatic translation of such descriptions into the explicit form which other software can understand. An example of existing work in this spirit is Ken Brakke's Evolver program (in continuing development at the Center), which can perform this sort of translation in the case of soap films and closely related shapes.

The general context in which differential-geometric descriptions-including those for soap films - can be expressed is that of partial differential equations (PDEs). These are equations which specify how a number of different quantities (infinitesimally) change in relation to each other. Geometrical optimization problems such as our soap film can be systematically translated into PDE problems. To take a different example, a geodesic is usually defined as the "shortest" path between two points on a curved surface, but it can equally well be defined as the "straightest" possible path (i.e., one which experiences no acceleration or deceleration, other than that imposed on it by being constrained to the surface). The latter formulation is in terms of relative rates of change, and is therefore mathematically a PDE.

Because PDEs are so general, it is impossible to write software which can give a reasonable answer to an arbitrary PDE specified by the user. Fortunately, most PDE problems encountered in differential geometry are elliptic-meaning roughly that each unknown value in the problem is tempered by the values of unknown quantities nearby. (This 'temperance' is visibly true for the points that make up the shape of a soap film, for example.) The benefit of ellipticity for a computer program like CADiff is that numerical analysts have developed robust and efficient solution methods for elliptic PDEs. The main job of CADiff, then, is to make these solution methods available and practical in the context of differential geometry.

Burchard has found the Center's people and resources indispensable in the current planning/experimental phase of CADiff. His interactions with visiting and resident geometers-the "customers" of this software-have had significant effect on his conception of what the program should do. He is also working very closely with the Center's software staff on the crucial issues of modularity and interoperability-issues to which Center staff bring unparalleled expertise due to their collective experience with large mathematical software projects.

Ongoing research projects.

The scientific program of the Center derives from the ongoing research programs of the Faculty. These programs have flourished and interacted under the Center umbrella. There are substantial interconnections between the fields represented. Most of the education and outreach activities, and the work of the lab, are drawn from them.

The activities described here are organized under the intertwined areas: Manifold geometry and associated group theory, Optimal geometries, Dynamical systems, and Computational geometry and computer graphics. 


\section{Research in optimal geometries (minimal surface team).}

One of the central thrusts of research carried out under the auspices of The Geometry Center has been work in optimal geometries and geometric evolution processes. Such work continues a tradition born with the earlier Geometry Supercomputer Project.

Leadership in this area has been provided by Group members Jean Taylor and Fred Almgren who have established an ongoing "minimal surface team "devoted to collaborative studies on such problems. Members of the team during the past year included Fred Almgren (Princeton University), Rob Almgren (University of Chicago), Ken Brakke (Susquehanna University), Nelson Max (University of California, Davis and Lawrence Livermore National Laboratory), Andy Roosen (Rutgers University graduate student), John Sullivan (University of Minnesota), and Jean Taylor (Rutgers University).

It is unquestionably the case that such a team would not have come into being had the Center not been created, nor could it continue to function in anything like the manner in which it does except for the resources the Center provides. It may be that the minimal surface team itself is an experimental model for the way in which at least part of mathematical research will be carried out in the future. Although each individual on the team is more than able to do good research work on his or her own they have found that by working together that they magnify the impact of ideas and efforts. Also there seems to be something about computing which works better if people collaborate.

A central project of the team for several years now is a theoretical and computational study of growth phenomena such as occurs in the growth of a crystal from melt, solution, or vapor. It is a grand mathematical challenge to try to come to grips with spontaneous pattern formation which occurs under conditions favoring dentritic growth (such as produce snow flakes). Under these diffusion-controlled conditions finding ways to predict growth speed, dimensions, sidebranching behavior, etc. seems a necessary step in order to predict and control in a scientific manner the microstructure of metal alloys, etc.

One of the rewards of working under the overall umbrella of The Geometry Center, with its unique physical environment and computing expertise, is the expectation and realization that important things can happen in reasonable times. Over the past several years, Rob Almgren and Andy Roosen have been able to create crystal growing programs running in two space dimensions based on sophisticated mathematical algorithms; Almgren's program requires a sequence of variational minimizations of combinations of bulk and interface energies while Roosen's program is based on Taylor's crystalline variational calculus and uses interface shattering steps alternated with motion and heat diffusion. Rob's continued association with the computer expertise of The Geometry Center helped him obtain substantial start-up funds from the University of Chicago for the purchase of an SGI Crimson graphics workstation; he, incidentally, would not now be working on crystal growth problems had he not visited the Center several summers ago. Andy's work at the Center was a substantial factor in his obtaining a postdoctoral appointment at the National Institute of Standards and Technology for continued work at the interface between mathematics, computation, and materials science; it can be revealing to watch the development of a shy graduate student into a macho computer hacker!

This past year's annual gathering of the minimal surface team at The Geometry Center took place during three weeks in August. This was the year in which it began to attack 
crystal growth with diffusion in three dimensions head on. Rob managed to get experimental code running on simple three dimensional problems. Nelson Max assisted in this enterprise with a new program for volume visualization capable of showing a crystal surface colored according to the local temperature, surrounded by a cloud of glowing smoke representing the temperature field in space. Rob commented, "Now my challenge is to generate data worthy of such visualizationl"

Visualization is, of course, a major challenge in three-dimensional computations. In two dimensions, one can graph functions of $(x, y)$; and using the Geomview program (written by staff members of The Geometry Center) one can easily inspect all aspects of the resulting surface. For example, numerical instabilities in the interior of the domain show up as waves on the surface. In three dimensions one is working blind; one may visualize only a very few aspects of the data, such as contour surfaces, and to judge whether the computation is correct, one must rely on stability analysis and experience from two dimensions. The rate as which one can advance the state of the art in computation is closely linked to the current state of the art in visualization techniques. Improvement in visualization technology remains one of the central priorities of our Geometry Center enterprise.

\section{Research in dynamical systems}

The heart project (Peskin and McQueen).

The Center has supported the heart project in many ways, both tangible and intangible.

Participation in The Geometry Center has encouraged Peskin and McQueen to emphasize the geometric aspect of their cardiac research. This has turned out to have unexpected and fascinating consequences, such as the discovery that the fiber architecture of the aortic valve has a fractal character which is a consequence of the requirements of mechanical equilibrium.

Participation in The Geometry Center has brought them into contact with a new and exciting group of colleagues whom they might otherwise not have met, but who now influence their work through informal discussions at various meetings, at the Center and elsewhere. The sense of belonging to this group, of wanting to do work that will be interesting to this group, cannot be quantified but nonetheless has a profound influence.

In other tangible ways, the Center has proven valuable for the heart project. Partial salary support for David McQueen, provided by The Geometry Center, has kept the heart project alive. An IRIS workstation, purchased by The Geometry Center and located in McQueen's office, is the principal window through which Peskin and McQueen view the results of their computations. Much-needed supercomputer time has kept them in business when they would otherwise have had to put the project on hold. They have used the Center's MinneView program to obtain effective three-dimensional graphic images of their results. Moreover, they obtained valuable help in the use of MinneView from Robert Almgren, who happened to be on site and whom they knew because of their participation in the Center. 
Bifurcation theory, sympletic maps in four dimensions, and celestial mechanics (R. McGehee and coworkers).

R. McGehee and B. Peckham studied resonance surfaces for two-parameter families of diffeomorphisms on $\mathrm{R}^{2}$. A standard problem in bifurcation theory is the determination of the set of parameter values for which a certain type of periodic orbit exists. These so-called "resonance regions" can be viewed as the projection to the parameter plane of two-dimensional "resonance surfaces" embedded in $\mathrm{R}^{4}$ (the Cartesian product of the parameter space and the state space). In earlier work, Peckham classified these surfaces and characterized classical bifurcation sets as features on the surfaces. This fall, McGehee and Peckham produced a video visualizing various special cases of these surfaces as they are embedded in $\mathrm{R}^{4}$ and illustrating the utility of viewing classical bifurcation theory in this more geometric way.

As an outgrowth of their work, McGehee and Peckham discovered a way of viewing homoclinic orbits for diffeomorphisms on $\mathrm{R}^{2}$ as surfaces in $\mathrm{R}^{4}$. This discovery not only provides new insights into properties of these orbits, but also leads to a new numerical algorithm for the computation of homoclinic and heteroclinic orbits for a large class of families of diffeomorphisms.

Eduardo Tabacman's thesis, Computation and Visualization of Homoclinic Orbits for Symplectic Maps, was written under the direction of R. McGehee. Last year Tabacman, a graduate student supported by the Center, produced and implemented algorithms for the visualization of stable and unstable manifolds for symplectic maps in dimension 4 . The goal was to understand the intersections of these manifolds, the so-called "homoclinic points." In the process, he discovered a powerful algorithm for the direct computation of these points. The algorithm is based on a variational approach taking advantage of the generating function for the map. The method appears to work better than previous methods on the standard examples and to converge even in cases where previous methods are known to fail. Furthermore, the same ideas appear to produce a new proof of the existence of homoclinic points in many important examples.

Center visitor Antoni Susin, who worked with McGehee for two months last Fall, studied the computation of connecting orbits on the collision manifold for the planar three-body problem. Properties of orbits passing close to triple collision in the classical threebody problem can be determined by studying the saddle connections on the collision manifolds. These connections change as the masses vary, and the problem becomes to understand how the connections depend on the masses. This problem can be reduced to the study of the linking of two circles embedded in a three-sphere. Using the tools available at The Geometry Center, Susin was able to illustrate the changes in the linking and to establish the existence of new saddle connections in the collision manifold.

Center visitor Alessandra Celletti, who came to work with McGehee, implemented her algorithm for the computation of KAM tori for symplectic maps in 4D. This algorithm is a technique for computing the Fourier expansion of an embedding of a two dimensional torus in four dimensions, taking advantage of special properties of the embedding. Graduate student Wen-Xiong Liu, who was supported by the Center, was able to visualize the embedded tori by combining the results of Celletti's computations with Center software. Inspired by the pictures, Celletti is continuing her attempts at a computerassisted proof of the existence of KAM tori in particular examples. 


\section{Research in hyperbolic geometry and combinatorial group theory.}

The year started with the publication of Word Processing in Groups (January 1992). Four of the authors (Cannon, Epstein, Levy and Thurston) are members of The Geometry Center. We believe that this is a significant contribution to research in geometric group theory, and that this view would be supported by independent referees. The book had its genesis in the Geometry Supercomputer Project, which was the predecessor of The Geometry Center. The Geometry Center played an essential role in the production of the book in a number of different respects. First, it brought the authors together physically on several different occasions. Although these occasions were scheduled around committee meetings, crucial progress was made in terms of the research. Second, the existence of The Geometry Center and the Geometry Supercomputer Project was an important element in persuading Britain's Science and Engineering Research Council to support Epstein's research at the University of Warwick. This made possible the production of software implementing a number of important algorithms in Word Processing in Groups. Third, the standards for this software have been substantially affected by their use in The Geometry Center. Many pieces of Geometry Center software use the Warwick automatic groups software. Fourth, the book was written using The Geometry Center macros, written by Silvio Levy (see above). Fifth, support by The Geometry Center gave Epstein the precious time in which it was possible to complete the work. The importance of The Geometry Center in the genesis and generation of the book is acknowledged through the use of The Geometry Center logo on its cover. A detailed account of how the creation of The Geometry Center relates to the creation of the book is given in its preface.

During the past year, work has continued on Thurston's book The Geometry and Topology of Three-Dimensional Manifolds. This is a book for which the mathematical community has been waiting impatiently for a very long time. Progress is inevitably slow because of Thurston's many duties to the mathematical community, but it is steady. This progress is a consequence of the existence of the Center and would not have taken place without it. Silvio Levy, who is employed by the Center, is continuing to devote time regularly to the book. Volume one is almost ready to go to the printer, but there are still numerous details which need attention, such as illustrations, the index, and so on. The ease of inserting illustrations has been greatly aided by the use of The Geometry Center Macros, used with LaTeX. These macros were written by Silvio Levy, and they are being increasingly used in the mathematical world for the production of both books and papers. For example, they are being used at the University of Pisa in Italy.

There were two workshops devoted to Thurston's book during the past year. These were during the periods December 12-19, 1991 and May 22-29,1992. These workshops are of great importance. Since Thurston is so busy, there is a natural tendency for his book writing efforts to fall by the wayside. The workshops have been periods of very rapid progress in the development of the book. The involvement of other people (in particular of Silvio Levy) means that significant errors have been found in the exposition; significant improvements in comprehensibility have been achieved. We believe that Thurston's book will break new ground for advanced books in mathematics, because of the very large number of illustrations; these have been drawn with the help of computer packages such as Illustrator and Mathematica. We also believe that the standards of exposition will also break new ground. The only other example we know of where important books have been written with the involvement of many people is the works of Bourbaki. These had a tremendous effect on the development of mathematics. The Geometry Center has made possible an intense collaboration of a rather different nature, which we believe will have a significant impact of a rather different nature. 
One of the most fruitful areas of progress over the past year has been in the field of combinatorial properties at infinity of hyperbolic manifolds. An important development in this connection is the Combinatorial Riemann Mapping Theorem, which is being worked on by Walter Parry and Jim Cannon. The Geometry Center has been of importance in furthering this work by providing a venue for these researchers to meet. Computing equipment provided by The Geometry Center, both in Minneapolis and at Brigham Young University, has been used to implement algorithms concerned with this work. A main impetus for the work is the Geometrization Conjecture of Thurston, which makes clear the important role of negatively curved groups in the study of threedimensional manifolds. The founding of The Geometry Center is part of the increasing realization by mathematicians of the importance of methods which are not only constructive, but which can be realized by practical programming.

Bill Floyd has paid several visits to The Geometry Center, usually at the same time as Jim Cannon and Walter Parry. Bill Floyd is working with them on understanding combinatorial space filling curves, which is also important in the theory of threedimensional manifolds. Floyd has played an important role in developing code to help understand the Combinatorial Riemann Mapping Theorem. There have been steady improvements in theoretical and practical approaches which have stimulated each other.

Floyd has also assisted at several of the book-writing workshops devoted to Thurston's book on three-dimensional manifolds. In the reverse direction, Thurston has had a substantial influence on the work on the Combinatorial Riemann Mapping Theorem through his advice and suggestions. These came about because of the simultaneous presence in Minneapolis of different members of the Geometry Computing Group.

Three of Cannon's Ph.D. students, Eric Swenson, Blake Fordham, and Paul Shawcroft, continue to use Geometry Center facilities at BYU. Swenson will graduate in the spring with a thesis about negatively curved groups. Fordham seems on the verge of a very nice theorem about Thompson's group, and he has written a suite of computer programs by means of which he explores algorithms in Thompson's group. The programs are written in common lisp. Shawcroft is writing recognition algorithms for negatively curved groups. Three undergraduates at BYU are writing computer programs to support Cannon's research.

The Center has long had a program: knot evolver which, in a crude way, approximated the gradient flow of a $\left(1 / \mathrm{r}^{2}\right)$ potential. Center faculty member Mike Freedman with $Z$.-X. He and Z. Wang became interested in the theoretical foundations of this $\left(1 / \mathrm{r}^{2}\right)$ energy, $E$. These foundations are full of interesting mathematics. $E$ is Mobius invariant and majorizes the topological invariant "crossing number." From these two central facts much information flows: Round circles uniquely minimize energy, $E$ (round) $=4, E$ (b) $<23$ implies that $b$ is unknotted, and only finitely many knot types can be represented with energy below any given bound. In prime knot types minimizers for $E$ exist whereas in composite knot types the summands tend to repel and drift ever farther apart with the infimum of energy never achieved. Also strong regularity results for local minimizers are obtained. The key fact of Mobius invariance was first established imperically in computer studies before a mathematical proof was found (the proof is not trivial because regularization terms are not pointwise even exactly-preserved under Mobius transformations.) The numerical analysis of the gradient flow for $E$ is quite nontrivial (e.g., short time existence is not yet established) but there have been interesting suggestions, particularly by Peter Doyle, which may lead to a beautiful new knot evolver program, perhaps one that can often (is always too much to hope for?) untangle loops that are merely tangled and not knotted. 
Feng Luo, who is an expert on Kleinian groups, and is partially supported as a postdoc by the Center, has made a significant contribution to the question of knot evolution. Feng and Mike Freedman have proved that if a group $G$ of Mobius transformations leaves an unkotted simple loop invariant then that loop can be deformed through $G$-invariant simple loops to a round circle. To put the result in perspective, consider the very optimistic Conjecture A and its consequence, Conjecture B:

Conjecture A: Grad E exists and (round circles) is the only critical submanifold.

Conjecture B: (space of unknots in $S^{3}$ )/Mobius group $\sim \mathrm{pt}$.

Mike Freedman's current work in four dimensional manifolds exploits a computational scheme which generalizes "Massey products." This scheme-like spectral sequences-is a form of algebra with a strong spacial organizing principle. It is too early to tell if some automation of these algebraic arguments would be useful. The objective of this work is to formulate a new topological surgery obstruction for rapidly growing fundamental groups.

Regarding Freedman's work of the last decade, a great challenge in computer visualization would be to "draw" any of the exotic homeomorphisms produced by his theory. If a "formula" for the "big reimbedding theorem" could be obtained, then the crucial Whitney disks would be described as a limit set under iterations. Such a formula would have theoretical interest as well.

The past year's work of Center researcher Jeff Weeks involves theoretical work, programming, and user support, with significant overlap between the first two.

(1) Theoretical work

The most exciting theoretical progress this year is the discovery (jointly with Makoto Sakuma of Osaka University) of a triangulation for 2-bridge knot and link complements which they conjecture to be the canonical one (i.e. dual to the Ford domain). In December Weeks will write code which allows the computer program SnapPea to recognize 2-bridge knots and links from arbitrary projections.

Sakuma and Weeks have also found a simplified and generalized proof of the Tilt Theorem which allows the computation of canonical triangulations.

The 2-bridge knot triangulations are the only example this year of theoretical progress stimulating improvements to the computer program. In all other cases, the reverse has occurred: a programming need has led to theoretical progress. Most notably, Weeks found algorithms to (a) create an ideal triangulation for a partially Dehn filled multicusp manifold, and (b) drill out geodesics to create new cusps.

Algorithm (a) is significant in that users can now apply all of SnapPea's features (horoball packing and Ford domains, symmetry groups, isometry checker, etc.) to cusped manifolds expressed as Dehn fillings on other manifolds.

Equally significant, algorithms (a) and (b) together let the user move freely up and down the lattice of all cusped hyperbolic 3-manifolds, exploring them all.

The error checking in the above algorithms is of some mathematical interest, because it is so simple. The algorithms are guaranteed to work unless the 
manifolds contain essential annuli or compressing disks. The latter case is detected by computing the Euler characteristic of the boundary, which is done by seeing whether the number of tetrahedra in the manifold equals the number of edges.

[The impetus for the work on drilling and filling was a conversion in Minneapolis with Joe Christy (MSRI). Weeks and Christy had come to the Center to discuss plans for SnapPea and get the students started on a video; the conversion about drilling and filling was an unintended consequence. This is an example of the sort of interaction the center promotes.]

(2) Programming

The goal of this year's (and next year's) programming work is clear: to completely rewrite Snappea. There are five reasons for this:

\section{(A) Portability}

The graphical portions of the old version of snappea are tied to the Macintosh. In the new version, Weeks is writing a computational kernel which is independent of any particular user interface. Graphical user interfaces for a variety of present and future computing platforms can then be written, without modifying (or even looking at) the details of computational kernel.

(B) Generality.

Because the old version of SnapPea evolved over a period of seven years, it has many limitations. For example, horoball packings cannot be drawn for nonorientable manifolds, Dirichlet domains cannot be found for orbifolds, symmetry groups cannot be computed in cases where the canonical cell decomposition is not a triangulation, etc. The fundamental data structures in the new SnapPea are being designed from the ground up to accommodate as wide a variety of examples as possible in the most robust and natural way.

(C) Documentation.

The old SnapPea lacked adequate internal documentation. In the new version, Weeks is writing the proofs into the source files. Typically, the proof that an algorithm works appears at the top of a source file, and then local comments document each step.

(D) Future development.

The new SnapPea should provide a solid base for future development. Weeks is trying to make its fundamental data structures as general and robust as possible, so that limitations similar to those described in (B) don't arise in the future, as new and unforeseen features are added.

(E) New features.

The new SnapPea has features not found in the old version, such as the ability to compute cusp shapes during Dehn filling, the drilling and filling algorithms described above in the section on theoretical progress, and the soon-to-be-implemented algorithm to recognize 2-bridge knots and links. 


\section{(3) User support}

Weeks spends a lot of time responding to inquiries from users wanting to know how to apply SnapPea to some particular problem. But this is essential to making the best use of the program, so this time is well spent.

\section{Research in computational geometry, computer graphics, and statistical graphics.}

Work in these areas interacts with the Center in a number of directions; these involve interaction with Center staff and facilities as well as other Center faculty. These aspects of work as well as indirect interactions will be described in the paragraphs that follow.

Hanrahan's work involves the development and application of tools and ideas to geometric problems ranging from the practical to the theoretical. One aspect of his work involves the development of visualization tools of various types. Another aspect involves the use of mathematical techniques to develop algorithms for rendering realistic images and for developing geometric algorithms. An output of his work, in addition to traditional forms of communicating research, is the development of videos to explain some of the geometric algorithms he develops.

In recent work, Hanrahan and Mitchell, a graduate student who recently visited the Center, combined an understanding of differential geometry and geometric optics to develop an algorithm for providing realistic illumination models for rendering curved surfaces. Their work uses the Gaussian curvature of a geometrical wavefront to compute irradiance. This work will ultimately aid the mathematicians in The Geometry Center to create more insightful images. Currently, insights from these mathematicians are helping to create the algorithms.

Chazelle has been involved in the development of numerous new algorithms for providing optimal algorithms for a variety of geometric problems. His linear time triangulation algorithm solved an open problem of long standing. He has recently provided an optimal algorithm for computing the intersection of two convex polyhedra. This builds upon Dobkin's work (joint with Chazelle and joint with Kirkpatrick) for fast detection of polyhedral intersections. In work with his student Palios, he studied the problem of decomposing nonconvex polyhedra into convex parts (either tetrahedra or arbitrary, but convex polyhedra). They developed a simple algorithm which was optimal in many cases. In 1986, he and Edelsbrunner developed an optimal algorithm for detecting all intersections among pairs from a set of line segments in the plane.

What is interesting about Chazelle's work described above is that algorithms have been implemented (or are being implemented at present) for all the tasks described. In addition to the implementations, videos have been made (or are being made) that use the implementations to describe the algorithms. Two of these videos appeared last year to describe line segment intersection (Tal, Chazelle, Dobkin) and polyhedral decomposition (Palios, Phillips). The first video was done using tools developed at Princeton, the latter using geomview developed at the Center. Two new videos are currently being developed to describe polyhedral intersection detection (Dobkin, Tal) and triangulation of simple polygons (Bronnimann, Chazelle). These will benefit from joint developments of tools between Center staff and center faculty and their students.

Dobkin and his former student Barber have developed a robust algorithm for computing convex hulls in arbitrary dimension. The algorithms build on work of Barber and Hirsch developing a topologically correct data structure for representing imprecise polyhedra in 3D. A Center apprentice, Olaf Holt, needed just such a program for studying tilings of 
hyperbolic space via convex hulls in Minkowski space. David Epstein described the problem during his visit here, and it turned out that Olaf was already working in it. Olaf implemented the 4D code for general position, and they used a 4D Geomview module developed by another Center apprentice, Daeron Meyer. This gave a real understanding of what a 4D structure looks like, and it gave Barber a good intuitive basis for one of his research areas: handling singularities and imprecision in general dimension. Geomview is being used to aid in the visualization of output of the algorithm in 4D.

Palios and Barber were students of Center faculty members at Princeton. Each is currently a postdoc at the Center. Their continuing work on their dissertations has built a bridge between activities at Princeton and the Center.

Allan Wilks continues the development of an environment for doing statistical graphics. The $S$ environment he has created (with Becker and Chambers) contains tools of interest to other Center members. The context in which this work is being conducted is the $S$ language for data analysis and graphics (Becker 1988). S presents a good environment for interactive data analysis, and is often praised for its graphics capabilities. However, the graphics model is rooted in concepts that are several decades old (it is a tribute to this model that it has stood the test of time), and needs to be redesigned.

The redesign is happening at a number of levels, but perhaps the most interesting part of the work is the aspect that permits graphical experimentation. In the current system, it is possible to customize graphical displays either by slightly modifying one or more of the many "graphical parameters" that control the plotting environment, or by low-level primitives that draw lines, show text strings, etc. In the new system, all graphs are described by graphical objects, the return value of graphics functions. These are composed heirarchically, with the lowest level objects corresponding to sets of lines, text strings, and the higher level objects being combinations of these, etc., and then higher level objects being combined from other objects.

The new system is intended both to work in a production mode, where standard graphical displays are being made, and in an experimental mode, where new graphical ideas may be tried out in such a way that the new ideas are expressed as naturally as possible.

\section{Research faculty at the University}

The geometry seminar of the School of Mathematics is currently meeting in the Center. All its members who are computationally involved are associated with the Center: from minimal surfaces, Johannes Nitsche, and from dynamical systems, Richard McGehee.

Currently four math faculty have been bought out of one course each by funds provided by the University's match to the Center funding. In addition, John Sullivan, who will end his term as Center postdoc next fall, will continue his work as a tenure track assistant professor in the School of Mathematics.

As with other Center programs, the relationship of the Center to the School has grown over the past year, and we expect the relationship will continue to grow and deepen as the School becomes more oriented toward geometry and computing. With increasing stabilization and growth of the Computer Science Department, that relationship too should grow and prosper. Currently one of the Center postdocs in computational geometry will be a full time faculty member there during Winter Quarter.

Relationships with the College of Education are developing as well. Currently, the Center has a subcontract with the Geometry Forum at Swarthmore to supply a half-time college graduate student in math education to post items to its bulletin boards. Further, the 
Center consultant in education is a graduate student in the College, and his work with the Center has inspired his choice of Ph.D. thesis topic.

Individuals or teams exploring geometric structures, or organizing software development.

Here are a few typical examples not mentioned elsewhere.

Baumslag and team visited to study the operation of the Center in preparation for organizing their NSF funded Computational Group Theory project at the Graduate Center of City University.

Ken Brakke and Johannes Nitsche are working together in using the Evolver to study surfaces minimizing various functions of mean and Gaussian curvature.

Dennis Roseman has visited several times to make videos as his work on knotted spheres in 4D develops.

From November, 15, 1991 through November 30, 1992 there were 167 person visits supported by the Center, including 27 by Center permanent faculty. By comparison, for the 9.5 month period February 1, 1991 to November 14, 1991 there were 59 person visits, including 21 by Center faculty.

\section{Workshops.}

The Center can accommodate about 30 individuals in a computationally based workshop. The success of these workshops depends heavily on careful preparation by staff and intensive involvement by the staff during the workshop period in providing various user services: fixing bugs, porting software, assisting in video production, solving system problems, etc. To our knowledge, no other mathematics institute has the range and depth of computational/graphics resources available. Yet, being focused on computational intensive programs, the Center does not have the conference and visitor facilities of the traditional NSF mathematics institutes (DIMACS, IAS, IMA, MSRI). It is therefore natural, when it is appropriate, for the Center to run workshops in conjunction with a larger program sponsored by one of these institutes. Operating under one group of program organizers, there would be the Center part which would be computational aspects of the program; and the large institute part which would be the traditional conference during which the Center workshop participants would report on their activities and discoveries.

In the period from December 1, 1991 the Center sponsored two workshops each of which were focused on the computational aspects of the subjects: Computational Crystal Growers Workshop, February 24-29, 1992 (organized by Jean Taylor), and Visualization of Invariant Sets for Symplectic Maps in Dimension 4 (organized by Richard McGehee), March 9-20, 1992.

For March 22-26, 1993, the Center will sponsor a workshop on "Knot Theory" which will be focused on research and applications involving knots, including knot polynomials, the geometry of knot complements, physics and biology. The workshop will emphasize those aspects that involve the use of computing and visualization both as investigative tools and for purposes of displaying and communicating results. It is being organized by Lou Kauffman, De Witt Sumners, Jeff Weeks, and Jim White. 
For the year 1993-4, initial planning is underway for the following workshops: Computational Group Theory (in conjunction with a large workshop at DIMACS), January, 1994; Elliptic and Parabolic Problems in Geometry (in conjunction with a large program in differential geometry at MSRI), April, 1994.

\section{Communication of research results.}

The monograph, Word Processing in Groups, by David Epstein, Jim Cannon, Derek Holt, Silvio Levy and William Thurston, was published January, 1991. It is the definitive presentation of the theory developed under the Center (and formerly, the Geometry Supercomputer Project).

The first issue has appeared of Experimental Mathematics, a new quarterly devoted to the experimental aspects of mathematics research. Center faculty member David Epstein is Editor in Chief, staff member Silvio Levy is Editor, and a number of other Center faculty are on the editorial board. A notable contribution to the first issue was the article by Center faculty Jack Milnor on cubic polynomial mappings. (This was also the subject an inspiring talk by him at the jointly sponsored MSRI workshop on visualization which focused on the challenges of making sense of the four dimensional fractal set which is the connectedness locus. Milnor will be mentoring a forthcoming Center apprentice to carry on further experimental work on this four dimensional set.)

Center staff are paying a lot of attention to making it as easy as possible for visiting researchers to make their own videos by recording directly from workstations. For example, Roseman (lowa) was able to make over successive visits videos illuminating his study of knotted spheres in four-dimensions. Staff wrote custom visualization tools, modules for Geomview, to assist him in this effort. Similarly, John Maddocks (Maryland) made a video illustrating his work on bifurcations. These videos were all shown in conjunction with colloquium talks by the authors. In the Spring, Center faculty member Douady with Bodil Branner and others plan to come to complete their video, the detailed planning of which is already underway, of the dynamics of Julia sets.

The bottom line is that the Center has the expertise, or has direct access to the technical expertise, needed to make any mathematical visualizations deemed worthy in terms of content and usefulness in communication. 
III. Updated STC Data Base 


\section{CENTERDATA REPORT \\ $1201 / 92$}

Grant Number: 89-20161

Center Director: Albert Marden

Institution Name: University of Minnesota

Title: Computation and Visualization of Geometric Structs NSF Coordinator: Al Thaler

\section{Fiscal Year: 93}

Number of Faculty Participants: 18

Number of Non-Faculty Participants: 3

Number of Visitors: 119

Number of Post Doctorates: 7

Number of Graduate Students: 23

Number of Undergraduate Students: 10

Number of High School Teachers: 32

Ethnicity Summary

American Indian, Alaskan Native: 0

Asian or Pacific Islanders: 13

Black, not Hispanic Origin: 3

Hispanic: 6

White, not Hispanic Origin: 164

Unknown: 23

Nationality Summary

US Citizens: 150

Foreign Nationals: 55

Gender Summary

Number of Males: 173

Number of Females: 39

Sources and Amounts of Support for the STC (Per 1000s)

Received Support: \$776

Commited Support: \$0

Pending Support: $\$ 80$

Total: $\$ 856$

Faculty Funding Summary (Other Than STC/ Per 1000s)

Funding from NSF: $\$ 978$

Funding from DOD: $\$ 100$

Funding from DOE: \$O

Funding from EPA: $\$ 0$

Funding from NASA: $\$ 0$

Funding from NH: $\$ 0$

Funding from NOAA: $\$ 0$

Funding from USDA: $\$ 0$

Funding from Other Federal: $\$ 0$

Funding from Other: $\$ 269$

Total: $\$ 1347$

Faculty Reported STC Funding (Per 1000s)

Total: $\$ 272$ 
IV. Description of Outreach Activities 


\section{Outreach}

\section{Research and training program for undergradute students.}

Every summer since 1988 there has been a ten week summer program for talented and motivated college students. Last summer, 1991, 20 students were chosen from the 120 that applied. With the assistance of the Head Coach, if needed, each student finds a summer long project in an area of the mathematical sciences that involves computing and visualization. At the end of the summer, each writes a report of the activities, and these are gathered together and distributed as a Center research report. In addition, the students make a video anthology of their work. This past summer's video will be listed in the catalog and sold at modest cost by Media Magic.

For the summer 1993 program, Professor Tony Phillips of SUNY-Stony Brook will again be head coach. During the first week of the program, a number of distinguished mathematicians are invited to present possible projects to the students. For the next summer, these will include Blaise Morton of Honeywell, and Center faculty member Charlie Peskin of Courant Institute.

\section{Geometry and the Imagination summer courses for teachers.}

Summer 1991: taught by Conway, Doyle, Gilman, Thurston

Summer 1992: Chaos and Fractals, taught by Branner, Felsager, Hubbard, Vedelsby

Summer 1993: Computation, Visualization and Graphics, to be taught by Dobkin, Hanrahan, Sorenson, Souvaine.

For the past two summers, and planned for the coming summer, the Center has organized teams of four outstanding instructors to bring contemporary material to teachers, and in turn to give a group of talented and highly motivated expositors experience in working closely with teachers. Building on past experiences, the plan for next summer is to have a very intensive formal program six hours a day over 10 days. The teachers will be strongly encouraged to live together in the dorms because past evaluations show those who do get much more from the course.

Though the University extension division, the teachers will receive six credits upon completion of Mathematics 5025 and 5025X.

Thirty high school (including a few middle school) mathematics teachers can be accommodated in the program. Our intention is that most of the teachers will be from Minnesota to allow easier follow up and promote continued Center involvement, but representing the full range of schools (inner city, suburban, rural, private, etc.), with special effort spent on recruiting women and minorities (last summer, over $50 \%$ of the class were women, in contrast to the representation of women among the population of MN math teachers). In addition to the 30 teachers, the 20 college students from the Center's research and training program are also encouraged to take part in the course.

To do as much as we can to assist the teachers to prepare materials from the courses for use in their classroom, the Center has been successful in raising additional funds to allow some of the teachers to remain longer at the Center to prepare such materials, and then distribute them to all the class participants. The fruits of the past program are described below. 
Mike Freedman is an active member of the California coalition for mathematics. In this capacity he has reviewed the state framework for mathematics education for $\mathrm{K}-12$ with particular attention to the new text bok options for geometry. The Center's efforts to supply eductional tools and supplements will only be successful if its efforts are informed by a realistic knowledge of the present state-of-the-art in math education. Freedman's direct contact with the California "framework" will give a baseline for evaluating new educational tools.

In still more direct involvement, Freedman has been teaching a course of eight "lectures" in the Del Mar public school system to a group of second graders. The subject is regular solids. "We have assembled the five convex examples and one stellated monstrosity using foam balls and wooden skewers. Two of the students were moved by Euler's formula." Hands on experience of this type is necessary to think realistically about primary education.

At Harvard, David Mumford has taken over the role of the retired Andy Gleason in the large calculus project based there.

\section{The joint Center/MSRI/UCB graphics lab.}

The Center contribution is staff member Silvio Levy. The lab is open to undergraduate and graduate students, and to researchers at MSRI and Berkeley, collectively perhaps the largest concentration of mathematicians in the world. For example, in the lab Dr. Levy is working with Berkeley undergraduates in creating an animation explaining the homeomorphism between the complement of Thurston's knotted $Y$ and the gluing of two tetrahedra. The animation is based on a Mathematica program written by Levy.

Resources from the lab were also used in support of the MSRI workshop, Visualization of Geometric Structures, October 11-16, 1992. This was attended by over 120 persons and was strongly supported by the Center as part of the effort to disseminate the work of Center staff and participants. It was also an opportunity to discuss collaborations and connections with individuals and groups not currently involved in the Center. 
V. Management and Planning 
Executive Committee

Almgren, $F$.

Dobkin, D.

Epstein, D.

Hanrahan, P.

Keynes, H., Education Director

Marden, A., Director

Thurston, W., Codirector

\section{ORGANIZATION CHART \\ THE GEOMETRY CENTER}

November 1992

\section{External Advisory Board}

Hyman Bass (Prof. of Math, Columbia Univ.)

James Blinn

Frederick Gehring (Prof. of Math, Univ. of Michigan), Chair

John Guckenheimer (Dir. of Research Programs, Cornell Theory Center and Professor of Math, Cornell)

Deb Hughes Hallett (Prof. of the Practice in the Teaching of Math, Harvard)

Maria Klawe (Head, Dept. of Computer Science, Univ. of BritishColumbia)

Jill Mesirov (Dir., Mathematical Sciences Research, Thinking Machines Corp.)

Alan H. Schoenfeld (Chairman, Educ. in Math, Science \& Technology, Graduate School of Education, UC-Berkeley)

\section{Director}

A. Marden

\section{Codirector}

W. Thurston

Education

Director

H. Keynes

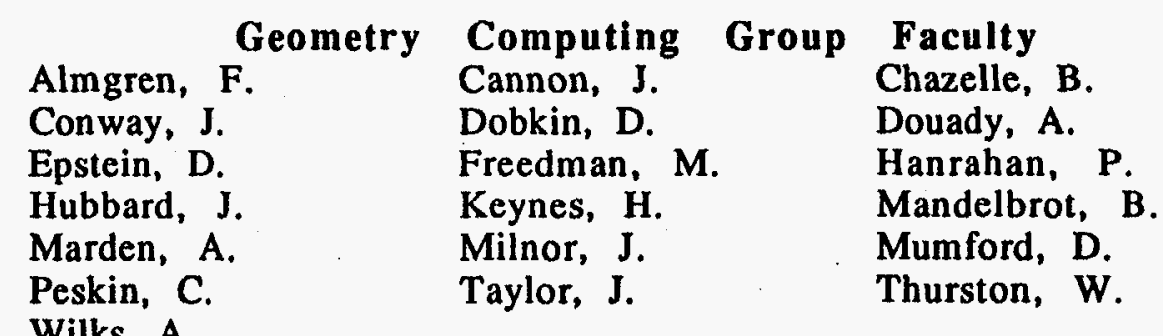

Staff

Administrative

Savoie, R.

Vail, A.

Videen, C.
Technical

Bertilson, S.

Fowler, C.

Gunn, C.

Holt, Olaf

Levy, Si,

Levy, St.

Meyer, D.

Munzner, $T$.

Phillips, $M$.

Upson, L.
Postdocs

Barber, C. B.

Burchard, $P$.

Goodman, $\mathbf{O}$.

Palios, L.

Sullivan, J. 
External Advisory Committee:

Hyman Bass (Prof. of Math, Columbia Univ.)

James Blinn

Frederick Gehring (Prof. of Math, Univ. of Michigan), Chair

John Guckenheimer (Dir. of Research Programs, Cornell Theory Center and

Professor of Math, Cornell)

Deb Hughes Hallett (Prof. of the Practice in the Teaching of Math, Harvard) Maria Klawe (Head, Dept. of Computer Science, Univ. of BritishColumbia) Jill Mesirov (Dir., Mathematical Sciences Research, Thinking Machines Corp.) Alan H. Schoenfeld (Chairman, Educ. in Math, Science \& Technology, Graduate School of Education, UC-Berkeley)

\section{Executive Committee:}

Frederick J. Almgren, Professor of Mathematics, Princeton University David Dobkin, Professor of Computer Science, Princeton University David B.A. Epstein, Professor of Mathematics, University of Warwick Patrick Hanrahan, Professor of Computer Science, Princeton University Harvey Keynes, Professor of Mathematics, University of Minnesota Albert Marden, Director and Professor of Mathematics, Univ. of Minnesota William P. Thurston, Codirector and Professor of Mathematics, UC-Berkeley

Center Faculty:

Fred Almgren, Princeton University James Cannon, Brigham Young University Bernard Chazelle, Princeton University John Conway, Princeton University David Dobkin, Princeton University Adrien Douady, University of Paris X1, Sud David Epstein, University of Warwick Michael Freedman, University of California, San Diego Patrick Hanrahan, Princeton University John Hubbard, Cornell University Harvey Keynes, University of Minnesota Benoît B. Mandelbrot, IBM and Yale University Albert Marden, University of Minnesota John Milnor, SUNY, Stony Brook David Mumford, Harvard University Charles Peskin, Courant Institute of Mathematical Sciences Jean Taylor, Rutgers University William Thurston, University of California, Berkeley Allan Wilks, AT\&T Bell Laboratories 


\section{Director's Report}

The year 1992 is the first full year of operation for The Geometry Center. I wrote in the 1991 annual report, "The Center mission of research and education supported by advanced computing, graphics and video technology opens many opportunities and possibilities for having an impact in each of these areas." Indeed. The story of 1992 is the story of incubating and cultivating opportunities, and of moving full steam ahead in established programs.

The "Permanent Faculty" has continued to prove an invaluable resource for Center activities; it provides a strong foundation and continuity of involvement for the scientific and education activities. Each member runs a strong research program at his or her own institution which is supported by a modest allotment of Center funds to assist in connecting intellectually and computationally to the Center and each other. For example Professor Keynes is using his support to leverage funds to support a postdoc in math education. Others are using Center support to provide partial funding for undergraduate or graduate students, postdocs, and needed graphics equipment. In retum, the Faculty serve as leaders for the Center's scientific program. They also participate in the education program and assist in recruiting and selection of postdocs, students, and other participants, in organizing workshops and conferences, in mentoring apprentices, in participating in the production of videos, and in other communication efforts (authoring Center sponsored books, assisting in the dissemination of information about the Center's activities, etc.).

\section{Research}

Through resident researchers and also the 'center without walls' aspect of The Geometry Center, there is a thriving research program. Currently in residence are Ken Brakke (sabbatical from Susquehanna University), Dan Freed (PYI from UT-Austin), Bruce Peckham (paid leave from UM-Duluth), Matt Richey (sabbatical from St. Olaf College). In addition, there are five postdocs. School of Mathematics faculty are increasingly active as well. The collective research of the permanent faculty remains a huge resource for the Center, and cannot be absorbed all at once. The uniquess of the Center's graphics lab and software development efforts is rooted on the seamless connection to mathematics research effected through both Center faculty and other researchers. All Center efforts are predicated on the requirement of high mathematical content, and this can be maintained only by direct and continuous involvment of researchers.

We expect continued growth in the number of mathematicians and computer scientists involved in all aspects of the Center program.

\section{Education}

Besides the successful programs carried out this year, as described earlier, an initiative has been taken which, if successful, will substantially enhance the Center's efforts in education. The culture of the mathematics profession has been evolving toward greater attention to and greater involvement in pedagogical issues. The activities of MER (Mathematicians in Education Reform) led by Center faculty member Harvey Keynes and Phil Wagreich, and the activities of the RGls (Regional Geometry Institutes), in no small way have promoted this change. In the Center this attitude has been even more evident because involvement in "visualization" itself leads to a desire to explain what is being seen. 
At the same time, the Center has been experimenting in ways to get more connection between teachers and contemporary research in geometry. For example, there is a parallel between making professional videos to communicate mathematics on the one hand, and working with teachers to explain contemporary mathematics on the other. Whatever the form, communication of mathematics is extraordinarily difficult; communication among mathematicians is built on layers of definitions and theorems, a process that leaves out the uninitiated. Identifying appropriate topics to communicate requires equal perspicacity. Thus, there is every reason for math educators and math researchers to come together to bring to bear their collective wisdom on a daunting problem of great importance.

From such thoughts, and practical considerations, the Center studied the possibility of a large materials development program. It had to be predicated on a true collaboration between teachers, math educators and mathematians working together for mutual advantage in a single physical environment with all aspects of the Center program. While having a broad vision, namely the creation of a new kind of software institute, at the core it must be focused on producing effective materials in geometry for precollegiate classrooms. It was clear that working amidst such a program would greatly benefit the researchers and software developers of the Center no less than (it is believed) working alongside enthusiastic, interested researchers would benefit the materials program. In fact, the Center would become the only math institute with a tightly integrated educational development program and, as such, would become an even more unique and stimulating place within the mathematical community.

The Center was able to recruit a wise and experienced mathematician as director of the proposed program in the person of Gene Klotz of Swarthmore. With Doris Schattschneider, he directed the project that led to Geometer's Sketchpad, a software product with associated written materials which is widely used in high schools. Klotz, in collaboration with the Center, has submitted to EHR a request for a planning grant. This would enable the detailed planning to proceed for what is envisioned to be a large and complex project.

If the planning grant is awarded, the Center itself will need to be reorganized to allow strong management and oversight for the new program while maintaining a seamless connection between that and already existing Center programs.

Returning to current Center activities, the apprentice program is also thriving. Apprentices are students who are taking six months or a year leave from college, or are between college and graduate school, or are taking a leave from graduate school. Each one is involved in the Center outreach program, and works with the Center to develop a long range plan of work. There are currently four apprentices. One is writing graphics software, another is working on advanced software for the NeXT, a third is programming a difficult construction in hyperbolic space, and a fourth has written some basic tools for investigating four dimensional objects and for animation. One of them is returning to school soon, but three more, including a Berkeley grad student, are arriving this Winter and Spring.

One of the six senior staff members is leaving in June, and we will be searching for a person who can serve the role of 'technical director'. Possibly this will be in conjunction with a faculty appointment in the computer science department. 
VI. International Contacts/Visits 
Center faculty members Douady and Epstein are based in France and England, respectively.

David Epstein runs a major SERC-funded computational program in computational combinatorial group theory at the University of Warwick. There are close scientific relationships between the Center and the program. Epstein is a frequent visitor to the Center and is a member of the Executive Committee.

Douady runs a program in holomorphic dynamics and plans to visit the Center with a team of collaborators in Spring, 1993.

The symposium "Geometry and Computers" was held in Tokyo, January 20-22, 1992. This was organized jointly by The Geometry Center and Professor Sadayoshi Kojima of the Tokyo Institute of Technology and several members of The Geometry Center attended. It was funded entirely by Japanese sources. Professor Kojima is trying to establish in Japan a center similar to ours. 
APPENDICES 

"Texture Segmentation by Minimizing Vector-Valued Energy Functionals: the coupled membrane model" (with Tai Sing Lee and Alan Yuille), Proc. European Conf. Comp. Vision, 1992, Lecture Notes in Computer Science 588, pp. 165-173.

"A Bayesian Treatment of the Stereo Correspondence Problem Using HalfOccluded Regions" (with P. Belhumeur), Proc. IEEE Conf. Comp. Vision and Pattern Recognition, 1992 (CVPR), pp. 506-512.

Filtering, Segmentation and Depth (with M. Nitzberg and T. Shiota), to appear, Springer Lecture Notes in Computer Science, 1993.

"Pattern Theory: a Unifying Perspective" in Proc. 1st European Congress of Mathematics, Birkhauser-Boston, 1993.

Palios, Leonidas

"Decomposing the Boundary of a Nonconvex Polyhedron" (with B. Chazelle), submitted to Algorithmica.

"Matching Upper and Lower Bounds for the Number of Extrema of a Polyhedron," Geometry Center research report, in preparation.

"Tetrahedral Break-up" (with M. Philips), Animation of Geometric Algorithms: A Video Review, Proc. 8th ACM Symposium on Computational Geometry (1992).

"Upper and Lower Bounds for Optimal Tree Partitions," submitted to the 20th International Colloquium on Automata, Languages, and Programming (1993).

Peskin Charles S. and McQueen, David M.

"Cardiac fluid dynamics", High-Performance Computing in Biomedical Research (Pilkington TC, et.al., eds.), CRC Press, Boca Raton, 1993, pp. 51-59 and plates 6-9.

"Mechanical equilibrium determines the fractal fiber architecture of the aortic heart valve leaflets." submitted to Am. J. Physiol.

Sullivan, John M.

"Monotonicity Theorems for Two-Phase Solids" (with Frank Morgan) accepted by Archive for Rational Mechanics and Analysis.

"Minimizing the Squared Mean Curvature Integral for Surfaces in Space Forms," (withLucas Hsu and Rob Kusner), accepted by Experimental Mathematics, 1992, vol. 1, number 3.

"Visualization of soap bubble geometries" (with Frederick Almgren, Jr.), Leonardo, 1992, vol. 24 number 3/4, pgs. 267-271.

Taylor, Jean "Curvature Driven Flows: A Variational Approach" (with Fred Almgren and Lihe Wang), Research Report GCG39 
"Flat Flow is Motion by Crystalline Curvature for Curves with Crystalline Energies" (with Fred Almgren), Research Report GCG43

"Simulation of Crystal Growth with Facetted Interfaces" (with Andrew Roosen), Research Report GCG36

Jeffrey Weeks

"Convex hulls and isometries of cusped hyperbolic 3-manifolds," in Topology and its Applications, to appear.

"Surgeries on the Whitehead link yield geometrically similar manifolds" (with C. Hodgson and R. Meyerhoff), in Topology 90, Proceedings of the Research Semester in Los Dimensional Topology at Ohio State University, ed. B. Apanasov, W. Neumann, A. Reid and L. Siebenmann, deJGruyter Verlag, Berlin, 1992.

"Symmetry groups of hyperbolic knowt and links," (with Shawn Henry), in Journal of Knot Theory and Its Ramifications, Vol. 1, No. 2 (1992) 185-201. 
Appendix II. External Advisory Committee Meetings 


\section{INTRODUCTION}

The External Advisory Committee visited the Geometry Center on 24 and 25 August 1992. Those present were:

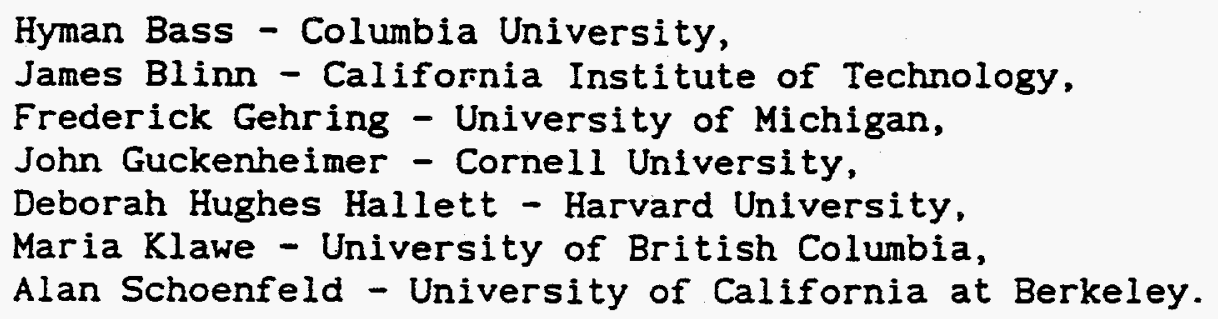

What follows is a very informal account of the Committee's findings delivered orally by various members of the Committee and organized under the following headings:

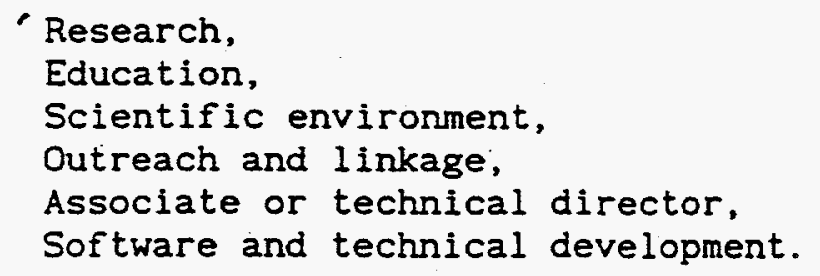

\section{RESEARCH}

The Committee was very impressed by the research that goes on here, particularly in the areas of hyperbolic geometry and associated topology and group theory where the work seems to have great depth and content. The Committee found even more fascinating the experiment of trying to do mathematics in an entirely different way which involves computation in fundamentally new terms than what has gone on before.

At the same time the Committee also feels that, implicit in the roster of permanent faculty and their interests, there is a broader research agenda which the Center ought to be exploring and the Committee encourages it to do so. The Committee does not want to mandate kinds of ideas. However one specific suggestion which arose is to ask Bernard Chazelle to convene a meeting of people in computational geometry at the Center and to see that the staff interact more with a large community of people in activities which, at least from the outside, seem to be closely related to much of the software research that is going on here.

The development of the technology and methodology for addressing certain mathematical issues may have a much broader application for other areas. The enterprise is inherently experimental and has generated new methods which probably even the people here could not have predicted. The Committee is pleased with what has happened so far.

There has not been sufficient awareness by the public of the potential uses and resources that have been put in place here. One of the main products of the Center is the culture and cohesion of the technical staff as both a resource to the research community and in integrating graduate students into such types of activities. One might, for example, consider developing some sort of access to the Center for graduate students at the University, possibly 
laboratory sessions at the enter. There they could inter. with the technical people and at the same time give the technical staff a more visible status in the functioning of the Center.

\section{EDUCATION}

The Committee was extremely impressed with the interaction of the Center, via Arnie Cutler and others, with the school teaching community. This was a. hard thing to do and it was well done. Cutler is a tremendous resource, really good at outreach. Given that this enterprise has flowered in so short a time, what the Center has done represents a truly substantial achievement.

One big question is to decide where to put resources in this interaction in the future. There are several types of activity which might be very valuable. One is developing software which can be used more easily at the school level. Another is developing actual written course materials, since it is not at all clear that the software developed by the Center will be supported by or in any way related to books currently available. A third. issue is whether the Center will actually become involved in training or assisting teachers in making the change.

The Committee hopes that the Center will play a role in initiating discussion of what kind of geometry is or isn't being taught at the school level and how it is related to that being offered at the college level. Whether the Center becomes involved in this as a continuing activity is another question. However it would, for example, be valuable if the Center could sponsor a conference where some of its permanent faculty reacted to what is going on in the schools and to the NCTM standards so that there would be some kind of bridge between the research and school communities.

The educational environment in which the technical staff works struck the Committee as the kind of intellectual community that is important for encouraging people, particularly women students, to go on to graduate school. What exists here could serve as a model for many other places.

Another question is how some of the software that the Center has been producing can be used not only here but in schools and at the undergraduate level. In this direction, the Center should consider having the faculty or technical staff give presentations at local, regional or national meetings so that people could see what is going on here. Meetings of the NCTM, AMATYC and MAA are possible forums.

The Committee was sorry that Harvey Keynes could not be here because it had questions about the Center's future plans and its long term vision for this part of its activities. There is an internal chemistry here which couldn't be prescribed and which has been exploited well in products and outreach material. But the question is - what happens as the Center goes from a group that is finding out who and what it is to a more stable entity? Should the Center go for a software institute, should it take seriously the mission of influencing $K$ through 12, should it do whatever is implicit in the promise of "On the shoulders of giants"? Behind these questions is the hope that the Center will take the lead in persuading serious mathematicians to think hard about new ways of doing mathematics, new ways of conceiving mathematics and new ways in which this can be communicated to students in $K$ through 12. That would be a wonderful enterprise. But it is not going to happen as the logical extension of the ad hoc activity that has gone on here so far. In other words, wonderful things have grown up here spontaneousiy 
rather than as a pa of a larger plan in which the nter defines its constituency and describes what it must do to affect them in certain ways. There are very serious issues here. How can one take the Center's emerging view of what geometry is and craft it in such a way that it is accessible to teachers and students in schools. Lovely diamonds of little products don't do things; people talk about them but they won't have a long range impact. The Center should take the time to reflect and formulate its plans.

An entirely different issue concerns the proposed Software Institute. If the Center does get one, this would have serious implications for the current staff and they are nervous about that. Of course the need for additional space would be a major problem. But more importantly, the people here love what they are doing on the platforms they have, they recognize that there would be a large new group to interact with scientifically, and that the many new demands for their time might result in a change of focus. They are afraid of being spread too thin. The acquisition of such an Institute would present a lot of managerial problems.

Overall, the educational issues appears to be a microcosm of everything the Committee has seen about the Center. It's a wonderful home grown place that is doing some really good things. On the other hand it is rapidly approaching a critical mass and the kind of informal, amorphous structure which the Center has now and which has worked well in the past, may not be adequate for what it will face in the next couple of years.

\section{ENVIRONMENT}

The infrastructure and resources which have been put together here are really impressive. The Center has done exceptionally well with respect to the technical staff, both in the choice of individuals and the way in which they work together. The Center has also succeeded in creating a remarkable computing environment, both for the people who are here and use it on a regular basis and for the people who come here for a few days and manage to walk in, start using it, and accomplish constructive things right away. This is a nontrivial accomplishment which the Center can proud of.

The Committee has also been impressed by other concrete things such as the video "Not Knot" and the newsletter "Imagine that". The actual concrete things being generated here are extremely impressive.

Along the lines mentioned earlier, the Center has achleved much with a small and informal organization. The Center has also grown by an order of magnitude during the past two years and there been a a substantial increase in the number of staff and post docs in just the past year. In view of this rapid change, the Center should consider putting in more structure. This does not mean making things more rigid but rather making it clearer, particularly for the technical staff, where their guidance is coming from and how they should interact with each other. This also means explicitly formalizing the fact that the Center values them as a resource. It is essential that the technical staff know that they should go to conferences, give presentations and interact with other people building similar software at other research institutions. The careers of the technical staff who are here for a longer period should grow as the Center grows. The Center has hired valuable people who are happy with what they are doing now. But this could change with the increasing level of activities and goals of the Center unless they have the kinds of support structure and framework that will recognize them and help them remain such a 
great team.

The fact that the computer system works as well as it does is kind of amazing given the somewhat amorphous structure of things. It works well now but one should keep an eye on it in view of the current rapid growth. The stack of video tapes from students is impressive. The Center seems to be able to turn out things at an impressive rate; a lot of other places are not able to do so. The people who did "Not Knot" spoke about the technical nuisance it was to create it; if the Center wants to do more such videos on that scale it should beef up the facility at the Center so that it will be easier to produce them. Also if the Center regards visualization as one its products, it should contact other people who have done visualization, design aspects, color schemes, timing and that sort of thing. Perhaps the Center should think of hiring somebody with expertise in video design if it wants to do more of this sort of thing.

\section{OUTREACH AND LINKAGE}

With a resource like this doing unique things and doing them so well, the Center has a responsibility to the country and the rest of the world to make sure that as many other people and groups as possible are aware of it and benefit from its knowledge and achievements.

The Center appears to being doing a superb job with respect educational outreach to schools. Its outreach activities with respect to other groups that are also doing research, based on computation and related to geometry, is less effective. This is probably just a matter of time. One can't do everything all at once. However the Committee would like to see the Center target some of the other groups that are leading in this area with the aim of seeing what it has to share with them, what it can learn from them, and what they can learn from it.

There are a number of such such groups doing software development related to computation geometry or geometric aspects. One group that would be a very good experience for the staff and post docs is at DEC SRC in Palo Alto: Ramshaw, Stolfi, Hershberger. Another group is the Computer Science Group at Cornell which has been looking at geometry with respect to robotics: Donald, Mitchel1. These are just two examples of excellent groups that are doing exciting things which are similar to but not the same as what is happening at the Center. Such contacts would provide an opportunity to get new users for Geomview and to pick up some of the software which other people are generating. The Center should invite members of these groups to come here and send members of the technical staff and/or faculty there.

Finally the Committee would be particularly happy to see some sort of activity between the IMA and the Center. Committee members who know people at the IMA will encourage them to take advantage of what the Center has to offer.

It would be wonderful to have either a faculty or staff member give a presentation at the Technology and Collegiate Mathematics Conference which is at Chicago this year. It is a huge conference where lots of people from 2 and 4 year colleges and from high schools would have a chance to see what is going on at the Center. One could also very easily give over again pieces of some of the summer courses as mini courses or workshops at AMATIC or MAA. That way the Center could reach another 30 to 50 high school teachers. The technical staff could do a lot of that quite well. 
Running the Geometry Center is a very big job, so big that the Committee discussed the advisability of having an Associate Director who is actually on the premises and could help out. It could be someone like a technical director who would give guidance to the technical staff as well as take over some of the activities normally associated with an associate directorship. This has to do with the question of structure and guidance referred to earlier. The Center's mode of operation is very sparse, informal and rather spontaneous, and it has functioned well up to this point. But the Center is reaching a threshold where something more deliberate about the way things are done and some more comfortable framework for the technical staff would seem to be appropriate.

From the Committee's point of view there is also a problem of information transmission. Members were presented with an assemblage of documents that collectively has answered most of its questions. However it has not been codified in a way which makes life easy for members at this meeting.

It appears as though there are some useful things which this Committee can do for the Center - offer critical commentary, act as an advocate and help with outreach activities. For example, there is no reason why the Committee could not meet with the Director of the IMA, Avner Friedman, as it did with the Department Chairman this morning. It could discuss things that might be happening and that have not happened up until now, it could learn ways which the Center might exploit the sort of outreach activities in which Friedman has been engaged, and it could make him aware of the resources here that he and his clients could make use of.

This is not directly responsive to the question of another administrative person. However it would be helpful for the Committee if for each of the major activities here - research groups in hyperbolic geometry and minimal surfaces, technical people, geometric visualization, education initiatives - a liaison person were named and put in the information loop so that Committee could remain better informed and make more productive use of time it spends on these visits. This person could, for example, be a member of the External Advisory Comittee itself.

The members of the Committee regard themselves as friends of the Center and want to help it carry out its mission. This means the Committee should be kept informed about what it is happening at the Center rather than being suddenly inundated by a stack of paper upon its arrival here. There should be a means for channeling information to the Committee. A technical director, an associate director or a public information person could be responsible for doing this.

It is quite common for a center like this to have a director who is a leading researcher in the area and who has the scientific vision, and to have an associate director who does things like organizing information for outreach and some of the hands on, nitty gritty management type things. Such an arrangement of ten works well. One thing the Committee sees a very strong need for is technical guidance, ongoing technical guidance. Though the technical staff is extremely happy working here - indeed they regard their positions here as paradise - technical guidance is the one thing which would make their If paradise. 
So these are very pres,minary reactions to a situation where the Committee has no definitive design solution but where it feels the need for some tightening and attention to the ways things are organized at the moment.

\section{SOFTWARE AND TECHNICAL DEVELOPMENT}

The above mentioned issue of a technical director speaks to this. The Center's software, evolving from research problems in hyperbolic geometry and minimal surfaces, is excellent as far as we can judge. The question of the Center's role in developing software for the broad vision of computation in geometry is something that is less clear. There is an enormous difference between the mathematical vision and expertise of the permanent faculty and the mathematical training of the most senior staff person, who deals with technical things on a day to day basis and is just one year beyond a PhD. This is a critical gap and something really needs to be put into place to give guidance to the staff. For however capable they may be, they are still very inexperienced with respect to the larger vision of where it is all going. The relationship between long term mathematical goals of the faculty and their connections with the day to day activities is something which really needs to be addressed.

The Committee is at a disadvantage in judging the sof tware developed by the Center: People have said the software is wonderful but nobody on the Committee has actually used it. Thus the Committee does not know if the software is wonderful or not. The concerns of the technical people seem to be reasonable - the modularity of the software and making things pipe together so that one can fiddle with one module and plug it together. What the Committee saw in the demos was a certain amount of chaos as far as user interface went in terms of - well you know we've got to put this and this and so forth. That may be inherent, a problem that is going to be solved, and then again it may not be.

To what extent has the Center actively investigated existing mathematical visualization sof tware? There may be nothing available which meets the current needs of the Center. On the other hand, it sounds as though Patrick Hanrahan came here and said "It looks like we need some simple little program to show shapes on a screen; let me tinker one together". Then somebody else said "Let me tinker something on top of that". The end result was a useful tool. But without actually actively studying the software it is not possible to judge its quality.

The Committee saw software feeding numbers to hardware which had some three dimensional rotations in it. There are programs that do this. Whether what has been developed here goes much beyond them is hard to say. This would be the job of a technical director - to be aware of what software exists and to decide if what is being developed is substantially better than what is already available or whether the Center is simply reinventing the wheel. Technical people like building things. When told "we need a software that does $x "$ ", the first thing on their mind is "I an going to write one myself". It's not "Let me see if something is already available." That's what a technical director is supposed to do - steer people away from that sort of a trap.

\section{FINAL COMRET}

One of the useful roles that the Geometry Center can play, and already has, is to serve as a model computing environment for the mathematical 
sciences.e The Centc. for Applied Mathematics at Cornell will be relocated in new facilities this fall. The Cornell Director was sufficiently impressed with the physical layout of the Geometry Center facilities that what he saw here had a significant influence on the design of the Cornell Center for Applied Mathematics facilities. In particular, the Cornell Center has adopted the idea of placing a large part of the computer facilities in open space combined with comfortable seating and round tables. Individuals must pass through these areas to reach their private workspaces. The hope is that this will encourage the kind of easy interactions involving computation work that occur routinely at the Geometry. Center. 
Main Office (617) 495-2171

Undergraduate Studies Coordinator (617) 495-9116

Graduate Studies Coordinator (617) 495-2170

Fax (617) 495-5132

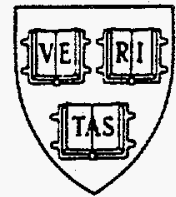

October 26, 1992
Science Center 325

One Oxford Street

Cambridge, Massachusetts 02138

Internet: math.harvard.edu

Bitnet: humal.bitnet

Professor Al Marden

The Geometry Center

1300 South Second Street

Minneapolis, MN 55454

Dear Al:

During my visit to The Geometry center, I believe I promised to write to you with some suggestions about making connections to secondary schools. Here they are:

1. Have Arnie Cutler or staff members give presentations of center work at local and regional NCTM meetings.

2. Continue the summer workshops for teachers.

3. Write articles for the Mathematics Teacher journal.

4. Consider establishing a collection of materials describing the various methods of teaching geometry at the secondary school level. This could include books, software, course descriptions, syllabi, sample problems. Make summary of materials widely available (NCTM meetings, etc.).

Many teachers have questions about what a geometry course should consist of, and would welcome the opportunity for a seminar, discussion and information.

5. Host or broker a discussion between the groups interested in what is taught in high school geometry: NCTM, college faculty, curriculum development groups. This conversation is long overdue, and it seems that The Geometry center would be the natural place to start it.

Please let me know if you'd like to discuss any of these ideas further - I'd be glad to. The fifth suggestion could, I believe, make an enormous contribution to education, as well as putting the center in a position of well-deserved prominence. 
page 2

I was extremely impressed by what I saw at the Center, in particular with your ability to make young researchers feel "part of the team." I'd be glad to help in any way to help continue this.

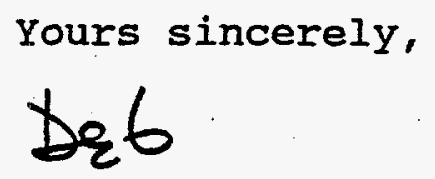

Deb Hughes Hallett

$\mathrm{DHH}: \mathrm{jm}$

CC: Fred Gehring

David Mumford 
Appendix III. Inventions, Patent Applications, Patents 
The Center has no inventions, patent applications, nor patents to disclose at this time. 
Appendix IV. Awards/Prizes 
The Center was awarded an Ars Electronica award in 1992 for its videotape "Not Knot." 
The Geometry Center University of Minnesota 1300 South Second Street

Minneapolis, MN 55454

Phone: (612) 626-0888

Fax: (612) 626-7131

admin@geom.umn.edu 


\title{
The Geometry Center 1991-1992 High School Mentoring Reports
}

\author{
Maria Nagan, South High \\ Elizabeth Callaghan, St. Anthony Village High \\ Karin Holt, South High \\ Ahna Reza-Girshick, South High
}

Tamara Munzner, mentor 


\section{School by Maria Nagan}

School is a set of three-dimensional fish that were created at the Geometry Center using a combination of Mathematica and geomview. Utilizing Mathematica and geomview meant that 1 needed to become more familiar with the Unix system and the NEXT computers. Before Alfred Gray left the Geometry Center in the Fall of 1991, he was kind enough to show a few of us what capabilities Mathematica had. He was just finishing a book called Curves and surfaces. This book ended up providing me with many ideas for my original fish's construction. School is actually one fish that has been regenerated ten times using matrices. The original fish consists of four different three-dimensional objects. They are a sphere, an ellipsoid, a paraboloid and half of an eightsurface.

All of my fish's original parts were produced with Mathematica. The body was the first section of the fish that I concentrated on, since it was the base for my fish. I knew that I wanted a football shape for the body. The problem was that I had no idea how to come up with an equation for it, so that I could graph it with Mathematica. Then one day, in my Linear Algebra class, we learned about the implicit form of the ellipsoid ax^ $2+2 b x y+c y^{\wedge} 2+2 d x z+2 e y z+f z^{\wedge} 2$. So, 1 thought it would be simple to graph the ellipsoid using "Plot3D" with Mathematica. I learned, when "PIot3D" didn't work, that it had to be parametrized because the above equation was not a one-to-one function. Mark Phillips and a Math Analysis book helped me parametrize the implicit equation for the ellipsoid. We discovered that using this command with Mathematica would graph our desired shape successfully: ParametricPlot3D [\{asin[u] Cos[v], asin[u]Sin[v], bCos[u]\}, (u, 0, 2Pi\}, (v, $-P i / 2, P i / 2\}]$. Then, I figured that I could modify this equation, make $a=b$, and come up with a sphere. This sphere would serve as an eye. The fin was a bit more difficult to create. In the end, I went to Alfred Gray's book, Curves and surfaces, to find potential models for a fin. I found a paraboloid that would suit the fish fine but I also confirmed my previous equations, the ellipsoid and the sphere. Alfred Gray had Mathematica graphs of the ellipsoid, the sphere, and the paraboloid. The paraboloid is actually quite similar to the ellipsoid. The equation looks like this: ParametricP1ot3D \{ $\{\operatorname{asin}[u] \operatorname{Cos}[v], \operatorname{bsin}[u] \sin [v], \operatorname{cCos}[u]\},\{u, 0,2 P i\},\{v,-P i / 2, P i / 2\}$. In my particular case, I chose $a=0.5, b=3$, and $c=1.5$. The tail was the most difficult part of my project to find. I again scoped Curves and Surfaces to discover an eightsurface: ParametricPIot3D [ $\{\operatorname{Cos}[u] \operatorname{Cos}[v] \sin [v], \sin [v] \sin [u] \operatorname{Cos}[v], \sin [v]\},\{u, 0,2 P i\},\{v,-P i / 2$, $\mathrm{Pi} / 2\}$. I assumed that $\mathrm{I}$ could simply make $\{v, 0, P i / 2\}$, thus creating only half of an eightsurface. By the time I had all of my objects graphed on Mathematica, geomview was created for the Silicon Graphics computers. Geomview gives three-dimensional perspective to geometry. It enables me to rotate, position, and vary the size of an object. Geomview also allows me to combine and rearrange my figures. So, I translated all of my Mathematica graphics into OOGL file format and began working with geomview.

Once I was working with geomview, I put all of the fish's different components together. Geomview enables me to rotate and translate the components so that they form a fish. After the body parts were arranged, I chose separate colors for each of them. Then, I saved the shapes as one object. To make the ilusion of fins on the sides, I used a program called Graffiti. Graffiti allows me to draw vectors on the body's surface. So, now I had a complete fish. Then, I placed copies of the fish in different places. Geomview automatically records the matrices used to rearrange the objects. The same idea about saving many components as one applies here. I saved the ten copies of fish as one school.

The project on a whole was not this smooth. I originally was too ambitious given the time constraints and there were many experimentations with potential fish parts that failed. On the other hand, I also learned about Mathematica, the Unix system, MESH, INST, GROUP, LIST files, odd objects that l'II never use again, but most of all, patience. I would like to offer special thank yous to: Tamara Munzner, Alfred Gray, Mark Phillips, Karin Holt and Ahna Girschick. 


\section{Report of Elizabeth Callaghan}

I worked with the program geomview, specifically how to create its data files. Geomview is a program that allows you to create and then graph various shapes. Geomview can then do things with these shapes, such as: rotate, translate, zoom. Its data files can be of many types, but I concentrated on four: quad, off, mesh, and inst files.

Quad files are made up of quadrilateral surfaces. The data file is simply a list of quadrilaterals, with colors attached. Each quadrilateral is specified by its four vertices and color values. A triangle can be drawn be specifiying a quadrilateral with two identical vertices. With some computation these quadrilaterals can be used to create more advanced shapes.

Off files are made up of a set of polygonal faces. They are similar to quad files, but because of the data file structure they are much more compact. Once again, a variety of shapes can be created. Colors can be assigned to either the faces or to the vertices. The results of this can be very strange.

The base of a mesh file is an $x-y$ lattice of points. The data file specifies the size of the lattice. Then, each lattice point is assigned a $z$ or height value. I think that the results often resemble topography.

Inst files make a group of objects into one hierarchical object. With matrix operations you can translate, rotate, and scale the objects, before combining them into a single group.

After I had mastered the various types of data files, I began to create a more complicated object. I started of by creating a polygonal sphere, with an off file. I then colored it, added eyes, and finally I added a mouth. The result was a three-dimensional, purple pac-man.

After I had created this object, I decided to create a sequence of objects using inst files. After many trials and many errors, coming I finally succeeded in creating my sequence. I depicted one pac-man coming up on another, and then swallowing it whole. 


\section{Graphics, Lights, and Motion: Softtmage \\ Karin Holt \\ Mentoree at Geometry Center 1992}

Computer graphics have become very complicated, and movies have shown us how fun and interesting they can be. I wanted to leam how to do all kinds of neat stuff when I came to the Geometry Center, and it took me a long time to figure out that with the limit of tools, time, and patience that I worked under, I could never make anything nearly as sophisticated as the images that we see in the media around us. This frustrated me a lot, but later I realized that I had actually learned some interesting things, and that is what I plan to show you.

I started out learning about Mathematica, mostly because it is very popular with computer people in general, and I also hadn't quite decided how I wanted to go about creating my graphics. Mathematica is a good program for drawings that are described with mathematics, but I was more interested in a more informal approach, so I became aquainted with Renderman. I was fascinated by the textures that could be wrapped around images, and I designed a red marble cube to see how it was done. With that accomplished, I continued on to Softlmage, which let me create images using the mouse alone, and which I worked with for the largest part of my project.

In the program, Softlmage, the search for shapes begins on a three-dimensional plane, which is designated by grids which stretch out infinitely before the eyes. There are also three other grids which gives the Drawer perspective from cross-sections of the three planes (i.e. the $x-y$ plane, the $x-z$ plane, and the $y-z$ plane). To begin, the Drawer has the choice of drawing shapes with lines, or selecting from a menu of varied and fascinating geometric shapes.

The lines can be drawn to fit the points Drawer designates, or they can bend in a meandering way around the points to make the shape look more smooth and rounded. When this is done, the line can be rotated around an axis, enlarged and reduced, or completely mangled beyond recognition. When a group of lines finally look like some sort of shape, faces and colors can be assigned to it, making it look more like a complete object. Any number of objects can fill the screen, meaning that things can be coaxed into appearing as bicycles, trains, birds, television sets, or, as in my case, a table and lamp. When all of these parts have been wonderfully mastered, the next step is to put the scene in the right perspective. Lights can be created in the form of invisible lightbulbs, large floodlights, or general brightness. This usually takes a while to finish tastefully, because this tums out to be quite a picky topic. Then the camera (that is, the Drawer's eye) can do fantastic feats in turning, twisting, and running away so that the Drawer can see everything properly, and from the right angle. The most exciting part of all is when these creations are set free, and are given life. I didn't get very far in this region, but I have heard that bouncing balls, opening boxes, and walking people are indeed quite possible. This is like creating a cartoon, and I am sure that I would have loved to make one if I had had the time. What I did accomplish was a star whose points spin in circles (undesignated by myself, unfortunately). 
This is basically where my project ended, though I see now that there are many more things possible in SoftImage than I knew of at the time. My biggest lesson at the Geometry Center has been that computer graphics are really quite complex, if one wants to make something realistic, and that computer languages are (surprise!) very important to leam for more interesting graphics to be possible.

I want to thank Tamara Munzner her her incredible patience,and inspiring knowledge; Mark Phillips for his insight in explaining parts of the book, The Shape of Space; Stuart Levy for helping me leam more about Softlmage; and Ahna Girshick and Maria Nagan for telling me to do this, and doing things themselves, so I wouldn't be left all alone here in Computerland. 


\section{THE FIBONACCI SEQUENCE \\ $1,1,2,3,5,8,13,21,34,55,89,144,233,377$....}

\section{by Ahna Reza-Girshick 1991-92}

What do all these numbers have in common? Well for starters, this is called the Fibonacci sequence. Each number in the sequence is the sum of the previous two numbers. It was discovered by Fibonacci, not me. What I have done here at the Geometry Center is use the Mathematica program to further explore the Fibonacci sequence. After reading a little about the Fibonacci sequence, I discovered it was a lot more complicated then a simple number sequence. It is related to various ratios which can be found in plant leaf arrangements and sea shells. It is also claimed to be found in architecture in buildings such as the Greek Parthenon. Since $5,730,000.00$ I really had no idea what any of that meant, I decided to see if it was true and what I could do with it.

The first thing I did was to look at logarithmic spirals because they were mentioned in all my books as the natural 
curve found of shells. They also mentioned that it used the

Fibonacci numbers which confused me even more, so I decided

to look at the Fibonacci sequence.

I began (after learning how to get around on Mathematica)

with writing a basic function which would give me the

Fibonacci sequence:

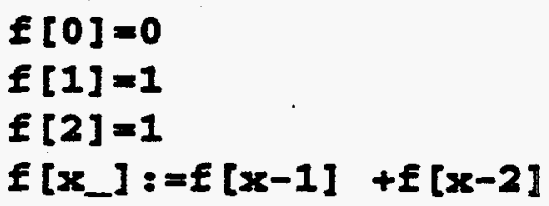

This function starts with $f[1]=1, f[2]=1, f[3]=2, f[4]=3 \ldots$...

Then I made another function, $g[x]$, which is the ratio of a

Fibonacci number to the number two numbers ahead in the sequence:

$g\left[x_{-}\right]:=f[x] / f[x+2]$

Table $[g[x],\{x, 0,10\}$.

$\{0,1 / 2,1 / 3,2 / 5,3 / 8,5 / 13,8 / 21,13 / 34,21 / 55,34 / 89$, $55 / 144\}$

From some books of plant formations, I learned that $g[x]$

gives the divergence in leaf arrangements. To find out what

anglular divergence is, $I$ altered the function $g[x]$, to $a[x]$.

$a[x]$ is just 360 degrees times $g[x]$ : 
$a\left[x_{-}\right]:=g[x] * 360$.

Just for fun, I decided to make a table of the angular

divergence:

Table $\{\{a[x]\},\{x, 0,20\}]$

$\{\{0\},\{180\},.\{120\},.\{144\},.\{135\},.\{138.4615384615385\}$, $\{137.1428571428571\},\{137.6470588235294\}$,

$\{137.4545454545455\},\{137.5280898876404\},\{137.5\}$,

$\{137.5107296137339\},\{137.5066312997347\}$,

$\{137.5081967213115\},\{137.5075987841945\}$,

$\{137.5078271759549\},\{137.5077399380805\}$,

$\{137.5077732599856\},\{137.5077605321508\}$,

$\{137.5077653937511\},\{137.507763536785\}\}$

I was really surprised when it approached a limit. As you

can see, the angular divergence approaches a limit of about

137.508 degrees and it is called the Fibonacci Angle. But it

was not until about 1900 that anyone noticed the Fibonacci

sequence or the Fibonacci angle in the seed patterns in flower

heads, snail shells, and some animal homs. The Fibonacci

angle in leaf arrangement gives the plants the minimum

superposition and the maximum exposure to the sun. So it

turned out to be something of interest after all.

Then I started reading about some neat properties of the

Fibonacci sequence. There is a geometric sequence which is

supposed to be the same as the arithmetic Fibonacci sequence. 
The relationship for this geometric sequence is:

$$
\operatorname{phi\wedge }=\operatorname{phi\wedge }(n-1)+\operatorname{phi\wedge }(n-2)
$$

The two solutions for phi are either $\mathrm{p}$ or $\mathrm{q}$.

$p=\left(1+5^{\wedge} \cdot 5\right) / 2$

1.618033988749895

$q=(-1+5 \wedge 0.5) / 2$

0.6180339887498949

So what do $\mathrm{p}$ and $\mathrm{q}$ and the Fibonacci angle all have in common?

After experimenting around for awhile, I came up with an answer to that question:

$137.508+360 q$

360.0002359499622

$(137.508+360 p) / 2$

360.0001179749811

\section{$360 / p^{\wedge} 2$}

\subsection{8}

The Fibonacci angle and $p$ and $q$ have $a$ lot in common! $p$ and $q$ are both usually referred to as the Golden Ratio. The Fibonacci Angle + the Golden Ratio (in degrees) $=360$ degrees. The Golden Ratio is what I was looking for all along, only I did not know it. That went back to my original interest in logarithmic spirals. A logarithmic spiral can be constructed from squares and "golden rectangles" as shown below. A golden rectangle is a rectangle whose sides are in the approximate ratio of the Golden Ratio. The diagram on the next page, taken from the book 
Leonard of Pisa and the New Mathematics of the Middle Ages by Joseph and Frances Gies, was made by taking a $2 \times 2$ square and adding a golden rectangle to the side. To do this, the distance EF had to equal to the distance EC. Both are equal to $\sqrt{5}$. This same procedure can be done to the rectangle GFBC by dividing it into a square and a rectangle. The rectangle that remains is a golden rectangle, which can also be divided into a square and a golden rectangle. This can go on and on to expand or contract the spiral, shown below.

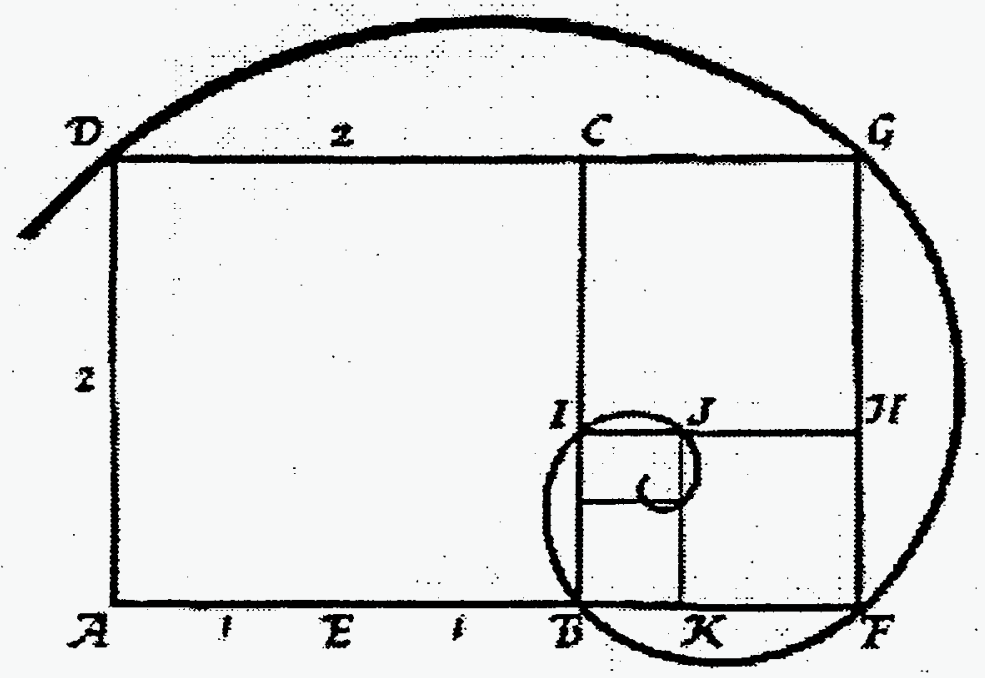

In this report I have discussed what I have learned about the relationship between the Fibonacci sequence, the Fibonacci Angle, the Golden Ratio, golden rectangles, and logarithmic spirals. What I did not discuss was all the dead ends and stupid mistakes I made along the way. But that probably would have bored the 
reader. Instead, I hope this gave you an interesting look of

how I have spent my time at the Geometry Center.

Special Thanks To:

Tamara Munzner, Mark Phillips, Karin Holt, Maria Nagan, and all the friendly computers and thinkers at the Geometry Center.

\section{Bibliography}

1.- Ahl, David H. More Than One Way to Skin a Rabbit; the Fibonacci sequence Revisted. Craetive Computing: April 1985.

2.- Cook, Theodore Andrea. The Curves of Life. Dover Publications, New York: 1979.

3.- Crouse, Richard. The Fibonacci Triangle. School Science and Mathematics: November 1987.

4.- Gies, Joseph and Frances. Leonard of Pisa and the New Mathematics of the Middle Ages. Thomas Y. Crowell Company, New York: 1969.

5.- Jean, Roger V. and Johnson, Majorie. An Adventure into Applied Mathematics with Fibonacci Numbers. School Science and Mathematics: Ocober 1989.

6.- Palmer, Laurence E. The Fieldbook of Natural History. McGraw-Hill: 1975.

7.- Rosinsky, Ned. How Plants Grow in the 'Golden Mean' Ratio. Fusion July-August 1984. 